\title{
On free vibration of laminated skew sandwich plates: A finite element analysis
}

https://doi.org/10.1515/nleng-2021-0006

Received Aug 23, 2020; accepted Jan 24, 2021.

\begin{abstract}
The present work emphasizes the determination of the fundamental frequency of skew sandwich plates with orthotropic core and laminated facings using different design parameters. Finite elements CQUAD4 and CQUAD8 of MSC/NASTRAN are used for obtaining fundamental frequencies, which are validated against available literature results. The influence of the skew angle, the ratio of the length-to total thickness $(\mathrm{a} / \mathrm{h})$ of the sandwich plate, and the ratio of the thickness of the core to face sheet $\left(t_{c} / t_{h}\right)$ on the fundamental frequency of skew sandwich plates are studied. Also, the influence of parameters such as the number of layers in the face sheet, laminate sequence, and fiber orientation angle on the fundamental frequency of laminated skew sandwich plates have been studied. It is found that the CQUAD8 element yields better results than the CQUAD4 element in the present study. The fundamental frequencies are found to increase with the increasing skew angle. The variation in fundamental frequency is negligible when the number of layers is large in the face sheet.
\end{abstract}

Keywords: fundamental frequency, non-dimensional frequency parameter, skew sandwich plate, skew angle, antisymmetric laminate, fiber orientation angle

\section{Introduction}

Skew sandwich plates are now a day frequently used in numerous areas like aeronautical, automobile, civil engineering, and in most structural applications. In skew sandwich plates, the effect of shear deformation is considerably more as compared to laminated composite skew

\footnotetext{
*Corresponding Author: Pavan Kumar Dhotre, Department of Mechanical Engineering, GM Institute of Technology, Visvesvaraya Technological University, Davangere, Karnataka-577006, India, E-mail: pavankumar-gmitrs@gmit.ac.in

Srinivasa C. V., Department of Mechanical Engineering, GM Institute of Technology, Visvesvaraya Technological University, Davangere, Karnataka-577006, India
}

plates, which was the reason behind the widespread applications of such plates. Also skew sandwich plate exhibits less weight, more stiffness, more structural efficiency, and more durability. Much research was made on sandwich plates on the free vibration behavior for more than two decades.

A linear analysis for bending and vibration of sandwich plates was employed for analytical and experimental investigations [1]. Also, refined plate theory was proposed on sandwich plates [7]. The free vibration analysis using higher-order shear deformation theory of sandwich plates [18], laminated composite and sandwich plates [6], skew sandwich plate with laminated composite faces were presented [8]. Free vibrations and buckling of the sandwich panel with a flexible core was investigated using a new improved high-order sandwich panel theory [11]. Free vibration analysis of laminated composite and sandwich plates using trigonometric shear deformation theory was performed [15]. Quasi-3D shear deformation theory was employed for thermo-mechanical bending analysis of functionally graded material (FGM) sandwich plates [35] and buckling and the post-buckling response was recorded from functionally graded carbon nanotube (FG-CNT) - magnesium (Mg) nanocomposite plate with interphase effect [31]. The modified stiffness method was applied to the dynamic analysis of sandwich plates [2]. An experimental modal study was conducted on a cantilever flexible plate underwater due to the hydrodynamic effect [32]. A study dealing with the comparison of free vibration responses obtained from four theories on composite truss core sandwich plates were presented. The natural frequencies of the sandwich plate are calculated by using the classic laminated plate theory, the first-order shear deformation theory, Reddy's third-order shear deformation theory, and a Zig-Zag theory [12]. Various shear deformation theories [13] were considered for the comparison based on the displacement fields [14].

Finite element analysis of composite sandwich plates was carried out based on Mindlin's plate theory [3]. The bending behavior [16] and free vibration response [17] using a four nodded rectangular finite element formulation based on a layer-wise theory, Static analysis [9], and the free vibration response [10] using an improved dis- 
crete Kirchhoff quadrilateral element based on third-order zigzag theory were presented. The p-Ritz method [5] on Skew sandwich plates and a numerical study were made on a sandwich plate to improve the dynamic effects of geometric design variables and material alteration [4]. The vibration parameters of sandwich plates were predicted by a spline finite strip method [19], harmonic quadrature element method [26].

Free vibration analysis of plates and sandwich plates was discussed using $\mathrm{C}^{o}$ iso-parametric finite element model [20], Two new $\mathrm{C}^{0}$ assumed strain finite element [21], $\mathrm{C}^{0}$ finite element model [22]. Fundamental flexural frequencies of isotropic and laminated composite skew plates [23], skew sandwich composite plates [27, 28] have been obtained using finite elements. Also, the experimental and finite element studies were carried out on free vibration of isotropic and laminated composite skew plates [24, 25]. The nonlinear static, buckling, and vibration analysis of viscoelastic micro-composite beam reinforced by various distributions of boron nitride nanotube (BNNT) with initial geometrical imperfection by modified strain gradient theory (MSGT) using finite element method (FEM) was presented [33]. A critical review of available literature for the prediction of the behavior of laminated composites and sandwich structures under hygrothermal conditions was carried out [34].

The present research focuses on the free vibration studies on laminated sandwich skew plates with simply supported and clamped boundary conditions. The face sheet consists of a laminated composite reinforced with graphite-epoxy and a heavy core (orthotropic). The key objective is to investigate the influence of the number of layers in the face panel, the ratio $[\mathrm{a} / \mathrm{h}]$, the ratio $\left[\mathrm{t}_{c} / \mathrm{t}_{f}\right]$, the effect of fiber orientation, the effect of the laminate sequence, the effect of boundary conditions, the effect of the skew angle on the sandwich plate's free vibration response. The paper is organized as follows: Firstly, for the free vibration analysis of the sandwich plate, convergence of the results gathered by both CQUAD4 and CQUAD8 elements is evaluated. The validation of the result by the present approach is compared to those available in the literature using converged element density. By implementing the mechanical properties as implemented in [20] for both the orthotropic face sheet (GFRPC) and the orthotropic core (Heavy), computational analysis is finally carried out to describe the effect of various geometric parameters, boundary conditions, and skew angle.

\section{Finite element formulation}

For thick plates the following equation (1) holds good:

$$
\left\{\begin{array}{l}
u \\
v \\
w
\end{array}\right\}=\left\{\begin{array}{c}
u_{0}+z \theta_{x} \\
v_{0}+z \theta_{y} \\
w_{0}
\end{array}\right\} \text { and }\left\{\begin{array}{c}
\theta_{x} \\
\theta_{y}
\end{array}\right\}=\left\{\begin{array}{l}
w_{, x}+\phi_{x} \\
w_{, y}+\phi_{y}
\end{array}\right\}
$$

Using five components $\mathrm{u}, \mathrm{v}, \mathrm{w}, \theta_{x}, \theta_{y}$, the displacement of the plate are fully described where $\mathrm{u}, \mathrm{v}$, and $\mathrm{w}$ are displacements along Cartesian $\mathrm{x}, \mathrm{y}$ and z-directions also $\theta_{x}\left(\mathrm{w}, \mathrm{x}\right.$, and $\left.\varphi_{x}\right)$ and $\theta_{y}\left(\mathrm{w}, \mathrm{y}\right.$, and $\left.\varphi_{y}\right)$ are total (bending and shear) rotations about $\mathrm{y}$ - and $\mathrm{x}$-axes, respectively, whereas, $\mathrm{u}_{0}, \mathrm{v}_{0}$, and $\mathrm{w}_{0}$ are the mid-plane translations along $\mathrm{x}, \mathrm{y}$ and $\mathrm{z}$ directions, respectively. Nodal displacements are used to describe the displacement $\delta_{j}$ at any point within the element by the following equation.

$$
\delta_{j}=N_{i} \delta_{\mathrm{ij}}
$$

Where $\mathrm{N}_{j}$ are isoparametric shape functions [30]. The stiffness matrix of the plate element assumes the form.

$$
[K]_{e}=\int_{A_{e}}[B]^{T}[D][B] d A
$$

Where,

$$
\{\varepsilon\}=[B]\{\delta\} \ldots
$$

$\{\epsilon\}$ being the strain vector, and $\{\delta\}$ the nodal displacement vector. $[\mathrm{B}]$ is the strain-displacement matrix, and [D] is the stiffness matrix given below.

$$
[D]=\left[\begin{array}{ccc}
A_{\mathrm{ij}} & B_{\mathrm{ij}} & 0 \\
B_{\mathrm{ij}} & \mathrm{D}_{\mathrm{ij}} & 0 \\
0 & 0 & \mathrm{~A}_{\mathrm{lm}}
\end{array}\right]
$$

Where,

$$
A_{i j}, B_{i j}, D_{i j}=\sum_{k=1}^{N} \int_{z_{k-1}}^{z_{k}}\left(Q_{i j}\right)\left(1, z, z^{2}\right) d z, i, j=1,2,6 \ldots
$$

And

$$
A_{k m}=\sum_{k=1}^{N} \int_{z_{k-1}}^{z_{k}} \kappa\left(Q_{l m}\right)^{k} d z, l, m=4,5, \kappa=5 / 6 \ldots
$$

Here, $\mathrm{Q}_{i j}$ is the element of off-axis stress-strain relations. $\mathrm{Q}_{i j}{ }^{k}$ relates stresses and strains in a $\mathrm{k}^{\text {th }}$ layer by the relation $\sigma_{i}{ }^{k}=\mathrm{Qij}^{k} \epsilon_{j}{ }^{k} . \mathrm{i}, \mathrm{j}=1,2,6$. Here $\sigma_{1}, \sigma_{2}$, and $\sigma_{6}$ denote $\sigma_{x}$, $\sigma_{y}$ and $\tau_{x y}$ respectively and $\epsilon_{1}, \epsilon_{2}, \epsilon_{6}$ denote $\epsilon_{x}, \epsilon_{y}, y_{x y}$ 
respectively. Whereas $\sigma_{l}{ }^{k}=\mathrm{Q}_{l m}{ }^{k} \epsilon_{m}{ }^{k}$ where $1, \mathrm{~m}=4,5$ and $\kappa$ is the shear correction factor taken as 0.8334 . The mass matrix of the plate element is given by

$$
[M]_{e}=\int_{A_{e}}[N]^{T}[\rho][N] d A
$$

$[\rho]$ being the density matrix functions.

The integration in every case is carried out over the area of the plate element. Generally, a 3-point Gauss quadrature is adopted to compute the bending stiffness of the elements, whereas 2-point integration is applied to calculate the shear stiffness, mass matrix, and element force vector. The governing equations, without damping being accounted for free vibration is

$$
M \ddot{x}+K x=0
$$

\section{Convergence and validation}

\subsection{Convergence}

The geometrical representation of the sandwich plate is as shown in Figure 1. The skewed sandwich plate with global and local coordinate systems is as shown in Figure 2. The displacement boundary conditions cannot be applied directly, due to the inclination of displacements to the skew edges. To overcome this, a local coordinate system $\left(\mathrm{x}^{\prime}, \mathrm{y}^{\prime}\right)$ normal and tangential to the skew edges is preferred.

A total number of elements in the plate model is optimized to get exact and consistent values. Consequently, it is essential to analyze the convergence of the values. The convergence was made on simply supported and clamped skew sandwich plates using CQUAD4 (four-node plate element) and CQUAD8 (eight-node isoparametric curved shell element) elements of MSC/NASTRAN. Skew sandwich plates with varying aspect ratio, length to thickness ratio, and the ratio of a thickness of core to facing for skew angles $0^{\circ}, 15^{\circ}, 30^{\circ}$, and $45^{\circ}$ using both the elements are evaluated. The converged detailed results are conveyed in Table 1. The material properties used are, for face sheets

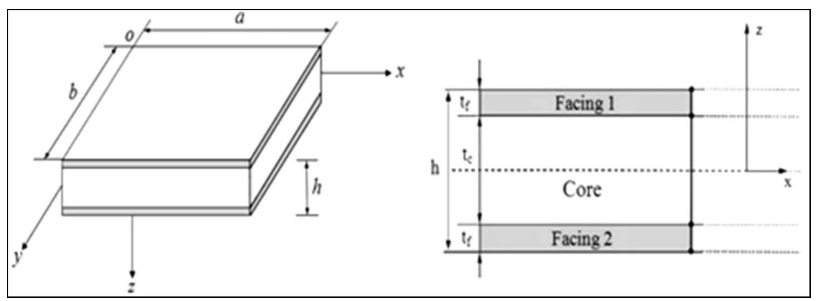

Figure 1: Geometry details of sandwich plate ( $0^{\circ}$ skew angle)

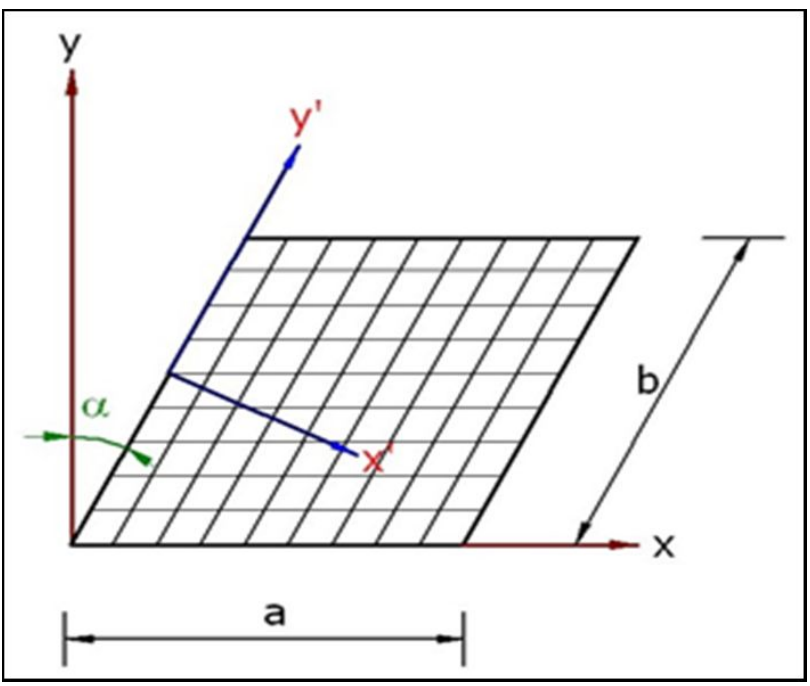

Figure 2: Finite element mesh model of flat skew sandwich plate

$\mathrm{E}=68.948 \mathrm{GPa}, \mathrm{G}=25.924 \mathrm{GPa}, v=0: 33, \rho=2768.0 \mathrm{~kg} / \mathrm{m}^{3}$ and core $\mathrm{G}_{23}=0.05171 \mathrm{GPa}, \mathrm{G}_{13}=0.13445 \mathrm{GPa}, \rho=121.83$ $\mathrm{kg} / \mathrm{m}^{3}[29]$.

\subsection{Validation}

Validation of the results from the elements used in the present study is made by matching up the values for the natural frequency found in the present study to the available literature values. The comparison is shown in Table 2 and 3, for clamped and simply supported boundary conditions respectively of a skew sandwich plate in $\mathrm{Hz}$. The material constants employed are similar to those used in [19]. The values found in the study are in good harmony with the literature results. Also for simply supported sandwich skew plates, the material constants are referred to as in [8].

Non-dimensional frequency parameter $\left(\mathrm{K}_{f}\right)$ of simply supported five-layered symmetric laminated composite skew sandwich plates with orthotropic core was determined by using the formula $\mathbf{K}_{f}=\mathbf{1 0 0} \omega \mathbf{a} \sqrt{ }\left(\rho / \mathbf{E}_{1}\right)_{f}$. The validation results for simply supported boundary conditions are shown in Table 6. The material properties employed for the study were as mentioned in [22].

From Table 1 to 4 it is observed that the CQUAD8 element gives accurate and converged results as then the CQUAD4 element. From now CQUAD8 is adopted in further work. 
Table 1: Convergence study for fundamental natural frequencies $(\mathrm{Hz})$ of simply supported skew sandwich plates $(\mathrm{a} / \mathrm{b}=1, \mathrm{a} / \mathrm{h}=10, \mathrm{tc} / \mathrm{tf}$ $=10)$.

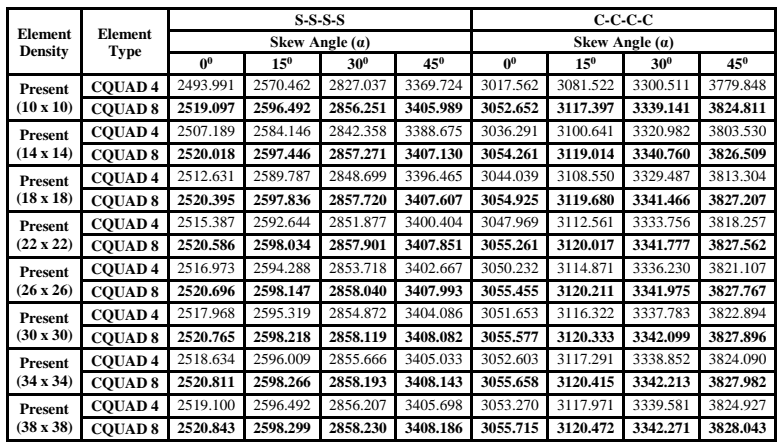

Table 2: Fundamental frequencies $(\mathrm{Hz})$ of clamped laminated composite sandwich plates with orthotropic core.

\begin{tabular}{|c|c|c|c|c|c|c|}
\hline \multirow{2}{*}{$\begin{array}{c}\text { Layup } \\
\text { Sequence }\end{array}$} & \multirow{2}{*}{ Authors } & \multicolumn{5}{|c|}{ Mode } \\
\hline & & 1 & 2 & 3 & 4 & 5 \\
\hline \multirow{5}{*}{$\begin{array}{c}30^{0} / 30^{0} / 30 \\
0 \\
/ \mathrm{C} / \\
30^{0} / 30^{0} / 30 \\
0\end{array}$} & Yuan [19] & 708.0000 & 1153.0000 & 1423.0000 & 1629.0000 & 1999.0000 \\
\hline & LEE (1966) [3] & 707.0000 & 1150.0000 & 1424.0000 & 1627.0000 & 1990.0000 \\
\hline & $\begin{array}{r}\text { Kanematsu (1988) } \\
\text { [1] }\end{array}$ & 720.0000 & 1181.0000 & 1463.0000 & 1683.0000 & 2074.0000 \\
\hline & Present CQUAD4 & 762.9000 & 1240.6000 & 1527.7000 & 1753.7000 & 2131.0000 \\
\hline & Present CQUAD8 & 763.6000 & 1241.9000 & 1529.9000 & 1756.7000 & 2135.0000 \\
\hline \multirow{5}{*}{$\begin{array}{c}0^{0} / 0^{0} / 0^{0} \\
/ \mathbf{C} / \\
0^{0} / 0^{0} / 0^{0}\end{array}$} & Yuan [19] & 692.3000 & 1191.0000 & 1366.0000 & 1720.0000 & 1954.0000 \\
\hline & LEE (1966) [3] & 691.0000 & 1200.0000 & 1353.0000 & 1715.0000 & 1997.0000 \\
\hline & $\begin{array}{r}\text { Kanematsu (1988) } \\
\text { [1] }\end{array}$ & 701.0000 & 1215.0000 & 1401.0000 & 1768.0000 & 2017.0000 \\
\hline & Present CQUAD4 & 746.8000 & 1296.8000 & 1454.0000 & 1846.1000 & 2128.9000 \\
\hline & Present CQUAD8 & 747.3000 & 1298.3000 & 1455.5000 & 1850.6000 & 2132.3000 \\
\hline \multirow{5}{*}{$\begin{array}{c}30^{\circ} \% \\
30^{\circ} / 30^{0} \\
/ \mathrm{C} / \\
30^{\circ} \% \\
30^{0} / 30^{0}\end{array}$} & Yuan [19] & 559.1000 & 1001.0000 & 1088.0000 & 1484.0000 & 1615.0000 \\
\hline & LEE (1966) [3] & 558.0000 & 997.0000 & 1090.0000 & 1478.0000 & 1604.0000 \\
\hline & $\begin{array}{r}\text { Kanematsu (1988) } \\
{[1]} \\
\end{array}$ & 567.0000 & 1024.0000 & 1115.0000 & 1528.0000 & 1670.0000 \\
\hline & Present CQUAD4 & 630.7000 & 1124.0000 & 1226.8000 & 1662.4000 & 1803.8000 \\
\hline & Present CQUAD8 & 631.5000 & 1125.8000 & 1228.9000 & 1667.6000 & 1807.5000 \\
\hline \multirow{5}{*}{$\begin{array}{c}0^{0} / 90^{0} / 0^{0} \\
/ \mathrm{C} / \\
0^{0} / 90^{0} / 0^{0}\end{array}$} & Yuan [19] & 628.3000 & 1011.0000 & 1273.0000 & 1521.0000 & 1604.0000 \\
\hline & LEE (1966) [3] & 628.0000 & 1007.0000 & 1272.0000 & 1517.0000 & 1593.0000 \\
\hline & $\begin{array}{r}\text { Kanematsu (1988) } \\
{[1]} \\
\end{array}$ & 637.0000 & 1032.0000 & 1313.0000 & 1568.0000 & 1658.0000 \\
\hline & Present CQUAD4 & 709.4000 & 1137.0000 & 1433.0000 & 1708.9000 & 1794.0000 \\
\hline & Present CQUAD8 & 709.7000 & 1138.1000 & 1434.3000 & 1712.3000 & 1796.2000 \\
\hline
\end{tabular}

\section{Results and discussion}

The present numerical study considers a variety of parameters, such as aspect ratio, a ratio of length to thickness of sandwich plates, ration thickness of face sheet to thickness of the core, skew angle, and boundary conditions of the sandwich skew plates. The results from the numerical methods are obtained by adopting material properties for further study hereafter as for Face sheet, $\mathrm{E}_{1}=206.84 \mathrm{GPa}, \mathrm{E}_{3}=5.1711 \mathrm{GPa}, \mathrm{G}_{12}=5.1711 \mathrm{GPa}, v_{12}=0: 25$, and $\rho=1603.1 \mathrm{~kg} / \mathrm{m}^{3}$ and core $\mathrm{G}_{13}=0.11721 \mathrm{GPa}, \mathrm{G}_{23}=0.24132$ GPa and $\rho=2351.2 \mathrm{~kg} / \mathrm{m}^{3}[20]$.
Table 3: Fundamental frequencies $(\mathrm{Hz})$ of simply supported laminated composite skew sandwich plates with orthotropic core.

\begin{tabular}{|c|c|c|c|c|c|}
\hline \multirow{2}{*}{\begin{tabular}{|c|} 
Layup \\
Sequence
\end{tabular}} & \multirow{2}{*}{ Authours } & \multicolumn{4}{|c|}{ Skew Angle $(\alpha)$} \\
\hline & & $0^{0}$ & $15^{0}$ & $30^{0}$ & $45^{0}$ \\
\hline \multirow{7}{*}{$\begin{array}{c}0^{0} / 90^{0} \\
/ \mathrm{C} / \\
0^{0} / 90^{0}\end{array}$} & Ibrahim [2] & 152.6000 & - & - & - \\
\hline & Yuan and Dawe [19] & 152.5800 & - & - & - \\
\hline & \multirow{2}{*}{ Ajay Kumar Garg [20] } & 166.3086 & 177.6942 & 217.7630 & 310.6456 \\
\hline & & 152.2992 & 161.7182 & 194.3770 & 267.3398 \\
\hline & Voyiadjis [8] & 150.9120 & 161.1690 & 195.8480 & 269.5720 \\
\hline & Present CQUAD4 & 152.3300 & 163.0240 & 198.8113 & 277.4106 \\
\hline & Present CQUAD8 & 152.3602 & 163.0580 & \begin{tabular}{|l|}
198.8503 \\
\end{tabular} & 277.4685 \\
\hline \multirow{7}{*}{$\begin{array}{c}\mathbf{0}^{0} / \mathbf{9 0}^{0} \\
/ \mathrm{C} / \\
\mathbf{9 0}^{0} / \mathbf{0}^{0}\end{array}$} & Ibrahim [2] & 146.0000 & - & - & - \\
\hline & Yuan and Dawe [19] & 145.9900 & - & & 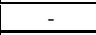 \\
\hline & \multirow{2}{*}{ Ajay Kumar Garg [20] } & 159.8275 & 170.7568 & 209.3430 & \begin{tabular}{|l|l|}
299.3778 \\
\end{tabular} \\
\hline & & 146.5089 & 155.5495 & 186.9801 & 257.5617 \\
\hline & Voyiadjis [8] & 145.0002 & 155.1070 & 188.7120 & 260.1220 \\
\hline & Present CQUAD4 & 145.6081 & 155.8880 & $\begin{array}{ll}190.2696 \\
\end{array}$ & 265.4776 \\
\hline & Present CQUAD8 & 145.6373 & 155.9213 & 190.3088 & \begin{tabular}{|l|l|}
265.5364 \\
\end{tabular} \\
\hline \multirow{7}{*}{$\begin{array}{c}90^{0} / 0^{0} \\
/ \mathrm{C} / \\
0^{0} / 90^{0}\end{array}$} & Ibrahim [2] & 159.3000 & - & - & - \\
\hline & Yuan and Dawe [19] & 159.3000 & - & - & - \\
\hline & \multirow{2}{*}{ Ajay Kumar Garg [2 } & 172.7237 & 184.5342 & 225.9660 & 321.4230 \\
\hline & & 158.0954 & 167.8775 & 201.7029 & 276.9311 \\
\hline & Voyiadjis [8] & 156.6980 & 161.1840 & 202.9450 & \begin{tabular}{|l|}
278.6170 \\
\end{tabular} \\
\hline & Present CQUAD4 & 158.9292 & 170.0157 & 207.1453 & 289.0373 \\
\hline & Present CQUAD8 & 158.9602 & 170.0502 & 207.1840 & 289.0932 \\
\hline
\end{tabular}

Table 4: Non dimensional frequency parameter $\left(\mathrm{K}_{f}\right)$ of simply supported laminated composite skew sandwich plates with orthotropic core.

\begin{tabular}{|c|c|c|c|c|c|}
\hline \multirow{2}{*}{\multicolumn{2}{|c|}{ AUTHOURS }} & \multicolumn{4}{|c|}{ Skew Angle ( $\alpha)$} \\
\hline & & \multirow{2}{*}{\begin{tabular}{|c|}
$\mathbf{0}^{\mathbf{0}}$ \\
9.8130 \\
\end{tabular}} & \multirow{2}{*}{$\begin{array}{c}15^{0} \\
-\end{array}$} & \multirow{2}{*}{$\begin{array}{c}30^{0} \\
-\end{array}$} & \multirow{2}{*}{$\begin{array}{c}45^{0} \\
-\end{array}$} \\
\hline \multirow{5}{*}{ Kulkarni and Kapuria [10] } & \multirow{3}{*}{ ZIGT FE } & & & & \\
\hline & & 9.8200 & - & - & - \\
\hline & & 9.8240 & - & - & - \\
\hline & 3D ZIGT & 9.8281 & - & - & - \\
\hline & ZIGT & 9.8300 & - & - & - \\
\hline \multirow{3}{*}{\multicolumn{2}{|c|}{ Chakrabarti and Sheikh [7] }} & 10.0510 & - & - & - \\
\hline & & 10.0520 & - & - & - \\
\hline & & 10.0530 & - & - & - \\
\hline Wang [5] & p-Ritz & 10.5550 & - & - & - \\
\hline Kulkarni and Kapuria [10] & TOT & 12.0880 & - & - & - \\
\hline Chalak and Chakrabarti [22] & HOZIGT & 9.8365 & 10.2467 & 11.6056 & 14.4349 \\
\hline \multicolumn{2}{|c|}{ Present CQUAD4 } & 9.2704 & 9.5546 & 10.5191 & 12.5896 \\
\hline \multicolumn{2}{|c|}{$\begin{array}{l}\text { Present CQUAD8 } \\
\end{array}$} & 9.2768 & 9.5612 & 10.5266 & 12.5988 \\
\hline
\end{tabular}

\subsection{Study on the effect of number of layers}

The effect of the number of layers on the fundamental frequency is assessed and results are graphically presented in Figure 3 and 4 in non-dimensional form $\mathrm{K}_{f}$ as well as the mode shapes in Table 5. The aspect ratio kept constant to 1 , skew angle, and the number of layers in the face sheet is varied for all sides simply supported and clamped edge condition. The following observations were made from the results,

- An initial increase in the layers increases the stiffness of the plate, later the added layers do not contribute to the sandwich plate's vibration response. Adding the number of layers in the face sheet allows the sandwich skew plate to accumulate in its weight. The largest impact is the core thickness that takes the majority of 
Table 5: Mode shapes of anti symmetric 5 layer $\left(0^{\circ} / 90^{\circ} / \mathrm{C} / 0^{\circ} / 90^{\circ}\right)$ skew sandwich plates.

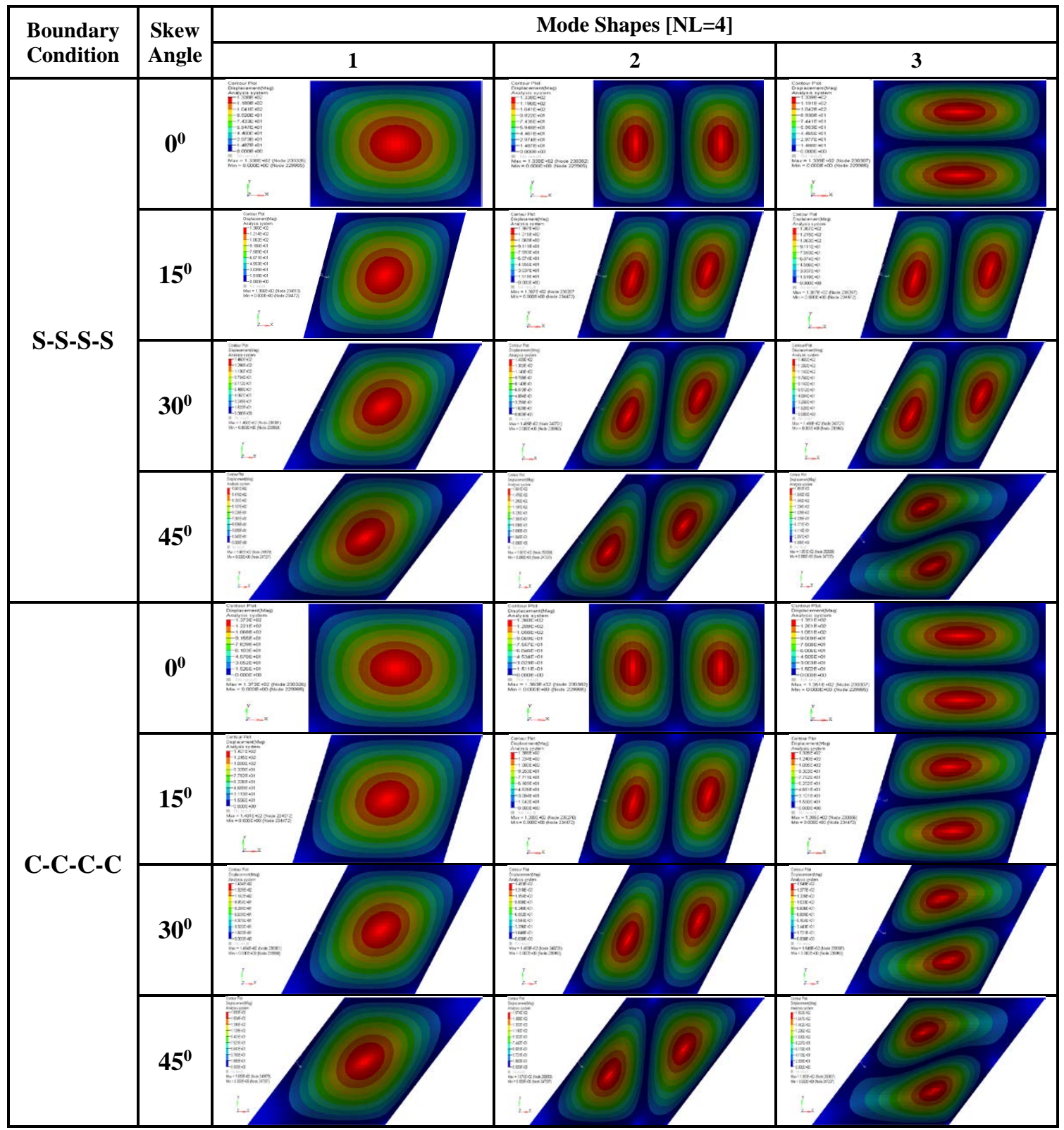

shear stress. The $\mathrm{K}_{f}$ initially increases up to 4 layers, as the number of layers of the face sheet increased and after this, the shift is constant or insignificant.

- The clamped condition has no degree of freedom free to rotate or oscillate in the plate element. This makes the plate stiffer compared to the simply supported one. Because of this, the value of $\mathrm{K}_{f}$ is higher for all sides' clamped condition than all sides simply supported.

- With the skew angle of the sandwich skew plates is increased, the value of $\mathrm{K}_{f}$ is found increasing in all cases of the parametric study.

\subsection{Effect of ratio of $t_{c} / t_{f}$}

Aspect ratio and $\mathrm{a} / \mathrm{h}$ ratio kept constant as 1 and 10 respectively, only the ratio $t_{c} / t_{f}$ is varied. The results are obtained for antisymmetric cross-ply, 5 layers simply supported and clamped boundary conditions for different skew angles. The $\mathrm{K}_{f}$ values are graphically presented in Figure 5 and 6. From the graph, the following observations are drawn.

Core Thickness, which takes the most of shear stress, is the key influencer for the vibration response of the sandwich skew plate. With the ratio of $t_{c} / t_{f}$ is increased, the 
Table 6: Mode shapes of symmetric 3 layer $\left(\theta^{\circ} / \mathrm{C} / \theta^{\circ}\right)$ skew sandwich plates.

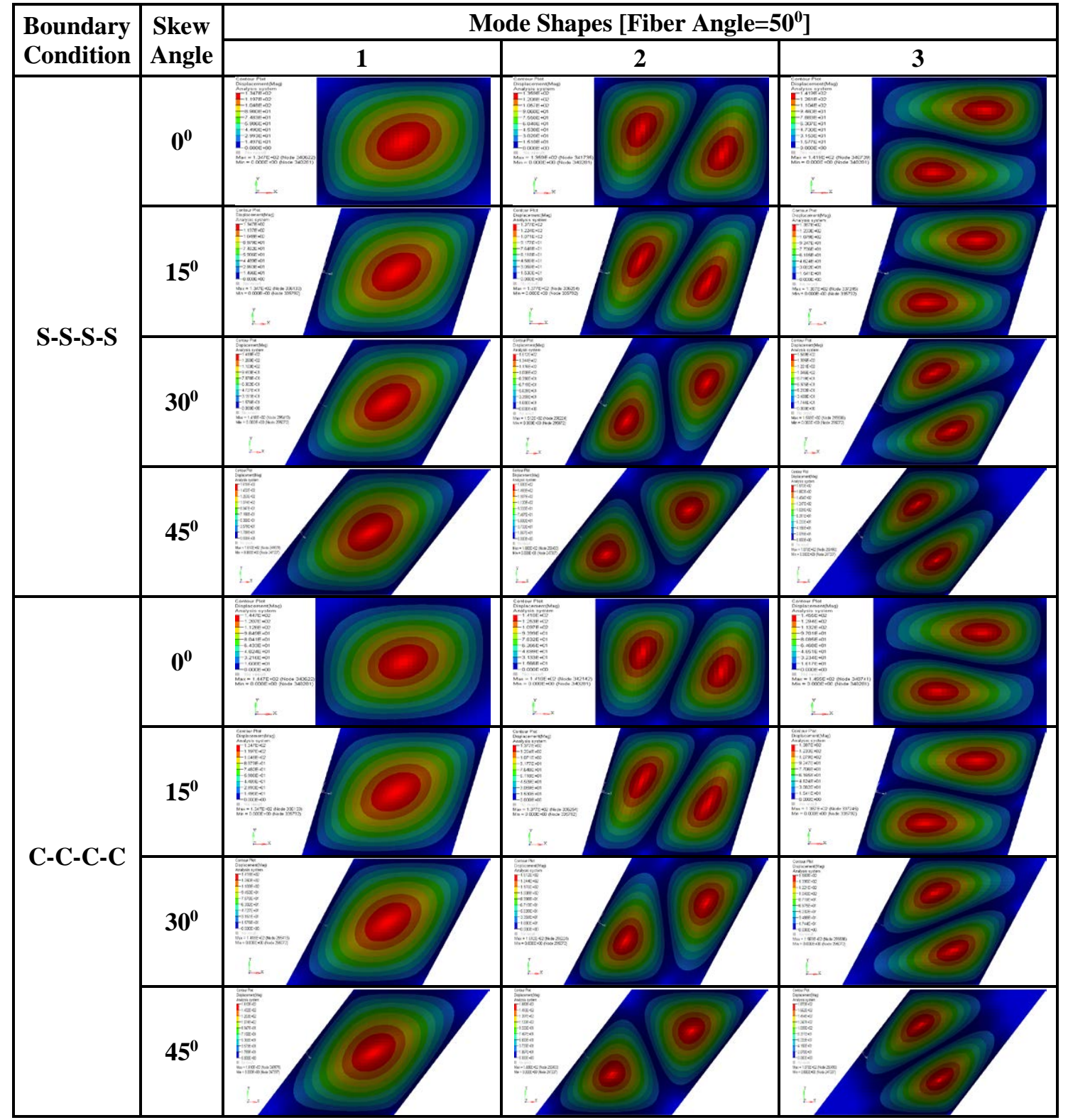

core thickness will also increase relative to the face sheet thickness. The higher the core thickness, the sandwich skew will become less stiff, and the $\mathrm{K}_{f}$ value for a given skew angle will be greatly decreased.

\subsection{Effect of ratio of $a / h$}

Aspect ratio and $t_{c} / t_{f}$ ratio kept constant as 1 and 10 respectively, only the ratio $\mathrm{a} / \mathrm{h}$ is varied. The results are obtained for antisymmetric cross-ply, 5 layers simply supported and clamped boundary conditions for different skew angles. The $\mathrm{K}_{f}$ values are graphically presented in Figure 7 and 8. From the graph, the following observations are drawn. A potential influencer is the core thickness compared to face sheet thickness. It is inappropriate to add more layers to the face sheet rather than vary the core thickness. The length of the sandwich plate kept constant only variable is the total thickness of the sandwich skew plate. When the ratio of $\mathrm{a} / \mathrm{h}$ is increased, the $\mathrm{K}_{f}$ value decreases considerably for a given skew angle. 
Table 7: Mode shapes of symmetric 5 layer $\left(\theta^{\circ} /-\theta^{\circ} / \mathrm{C} /-\theta^{\circ} / \theta^{\circ}\right)$ skew sandwich plates.

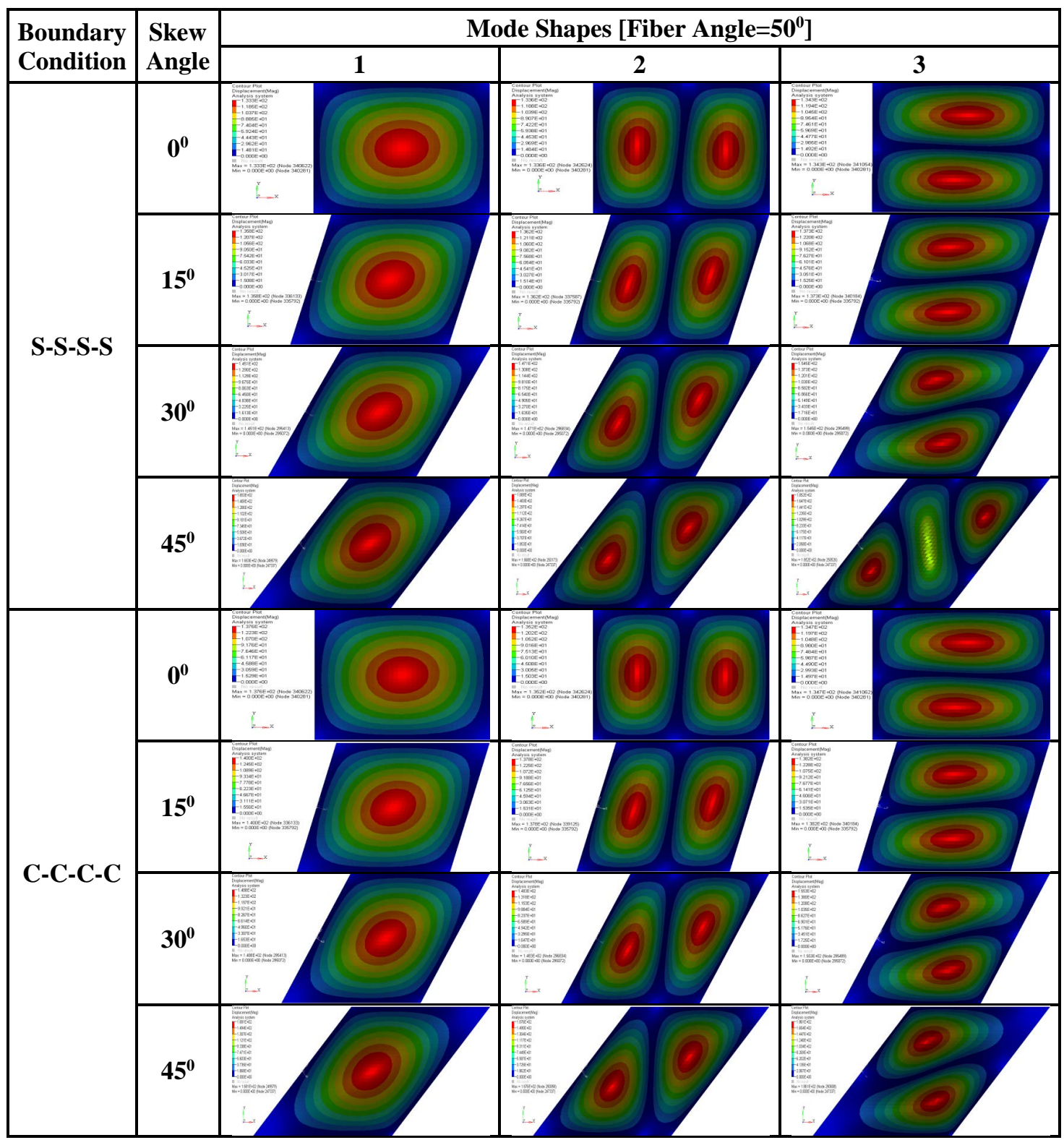

\subsection{Effect of laminate sequence}

A symmetric angle ply laminated skew sandwich plate is considered. Aspect ratio $1, \mathrm{a} / \mathrm{h}=10$, and $\mathrm{t}_{c} / \mathrm{t}_{f}=10 \mathrm{kept}$ constant, only skew angle and fiber angle are varied for the study.

\subsection{Symmetric three layer angle ply skew sandwich plates}

The results are obtained for the symmetric 3 layers simply supported and clamped boundary conditions. The $\mathrm{K}_{f}$ values are graphically presented in Figure 9 and 10 also the mode shapes in Table 6. From the graph, the following observations are drawn. For the $0^{\circ}$ skew angle, the $\mathrm{K}_{f}$ increases as an increase in the value of fiber angle. As the fiber angle is increased for skew angle $15^{\circ}, 30^{\circ}$, and $45^{\circ}$, the value of $\mathrm{K}_{f}$ initially decreases and then increases. 


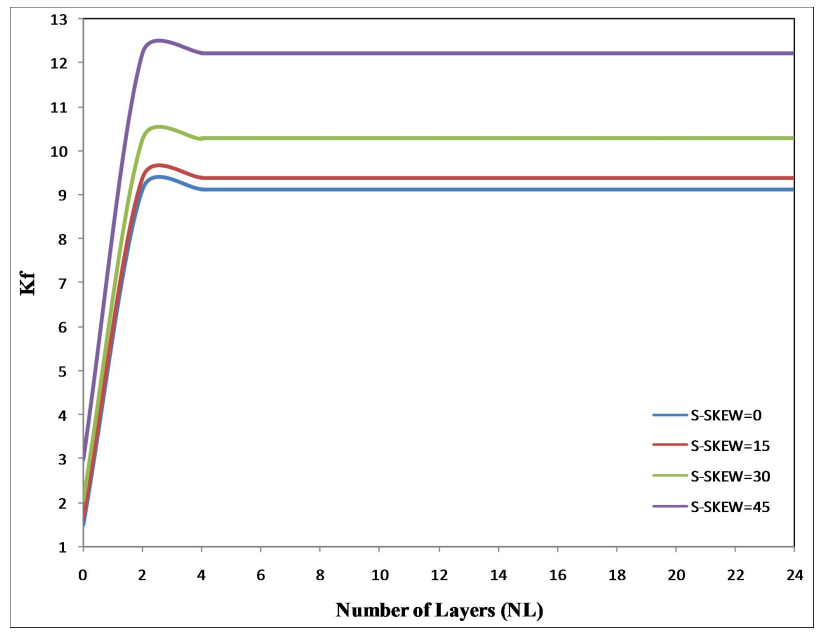

Figure 3: $\mathrm{K}_{f}$ values for laminated simply supported antisymmetric cross-ply $\left(0^{\circ} / 90^{\circ} / \mathrm{C} / 0^{\circ} / 90^{\circ}\right)$ skew sandwich plates

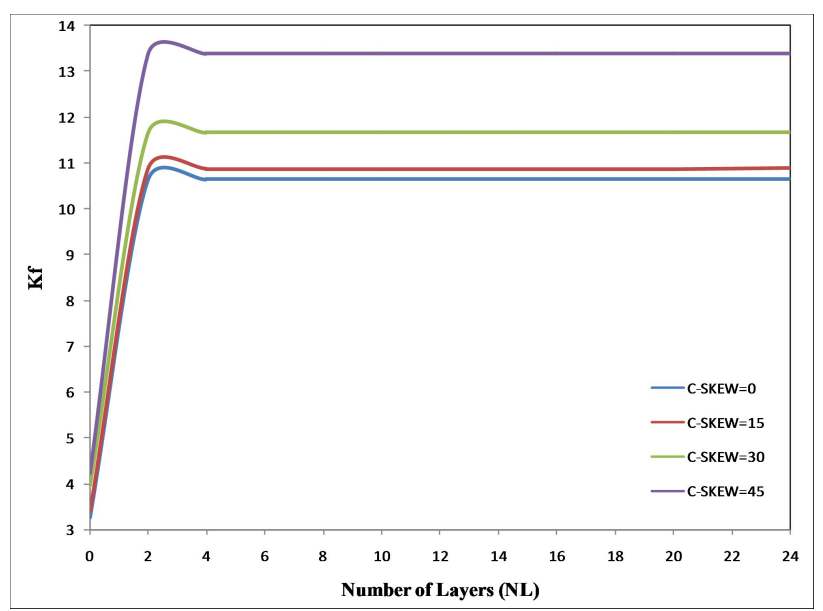

Figure 4: $\mathrm{K}_{f}$ values for laminated clamped antisymmetric $\left(0^{\circ} / 90^{\circ} / \mathrm{C} / 0^{\circ} / 90^{\circ}\right)$ cross-ply skew sandwich plates.

\subsection{Symmetric five layer angle ply skew sandwich plates}

The results are obtained for the symmetric 5 layers simply supported and clamped boundary conditions. The $\mathrm{K}_{f}$ values are graphically presented in Figure 11 and 12, and mode shapes in Table 7. From the graph, the following observations are drawn. As the fiber orientation angle increases, the $\mathrm{K}_{f}$ value increases and reaches a maximum value or symmetric about $52.5^{\circ}$ then decreases for simply supported and $50^{\circ}$ for clamped boundary conditions.

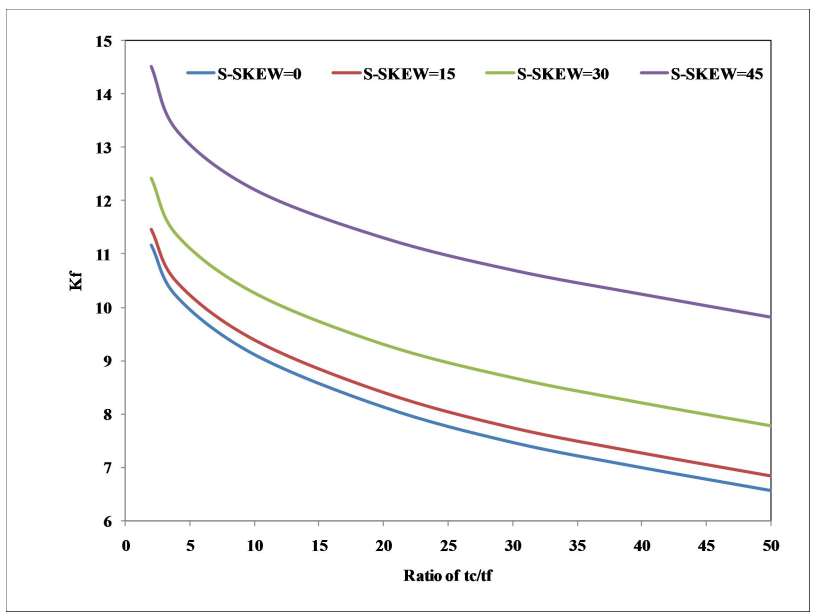

Figure 5: $\mathrm{K}_{f} \mathrm{v} / \mathrm{s}$ values of $\mathrm{t}_{c} / \mathrm{t}_{f}$ ratio for laminated simply supported antisymmetric cross-ply $\left(0^{\circ} / 90^{\circ} / \mathrm{C} / 0^{\circ} / 90^{\circ}\right)$ skew sandwich plates

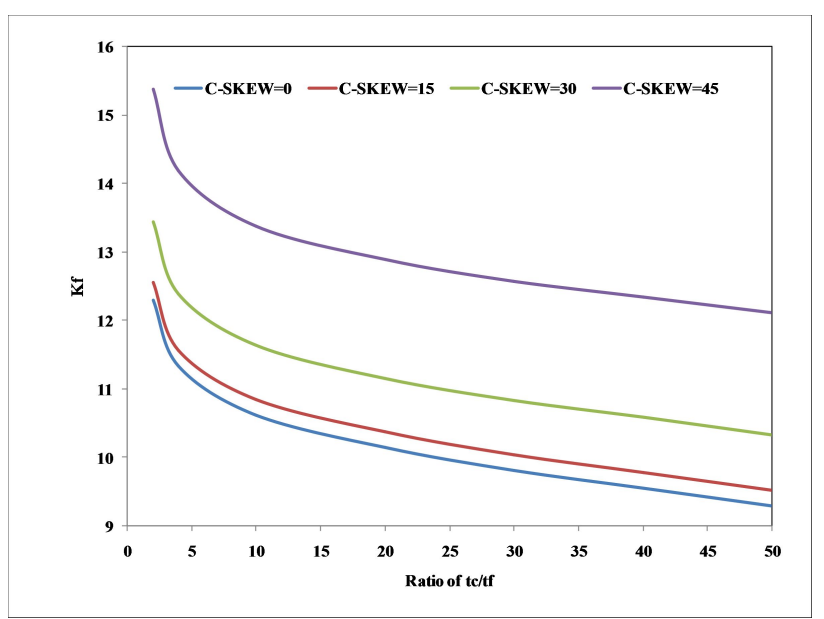

Figure 6: $\mathrm{K}_{f} \mathrm{v} / \mathrm{s}$ values of $\mathrm{t}_{c} / \mathrm{t}_{f}$ ratio for laminated clamped antisymmetric cross-ply $\left(0^{\circ} / 90^{\circ} / \mathrm{C} / 0^{\circ} / 90^{\circ}\right)$ skew sandwich plates

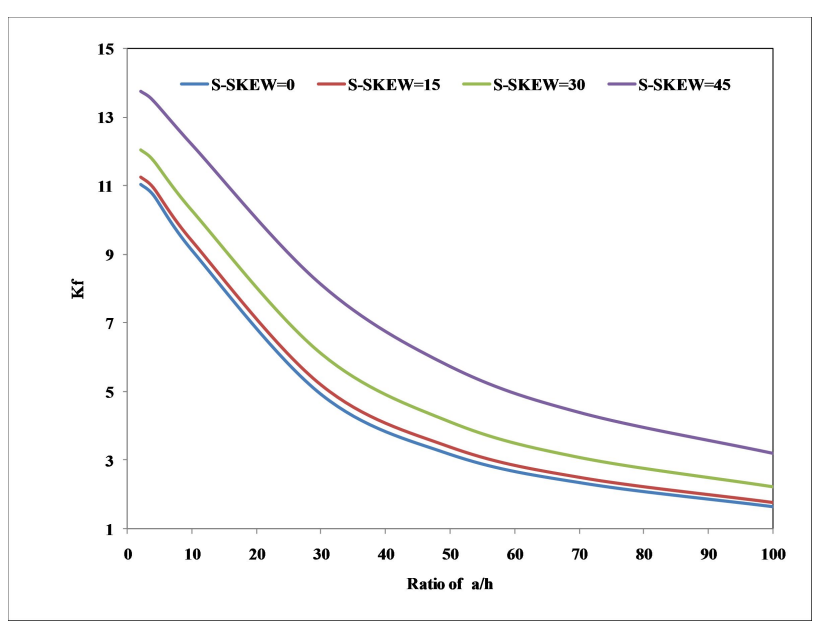

Figure 7: $\mathrm{K}_{f} \mathrm{v} / \mathrm{s}$ values of a/h ratio for laminated simply supported antisymmetric cross-ply $\left(0^{\circ} / 90^{\circ} / \mathrm{C} / 0^{\circ} / 90^{\circ}\right)$ skew sandwich plates 


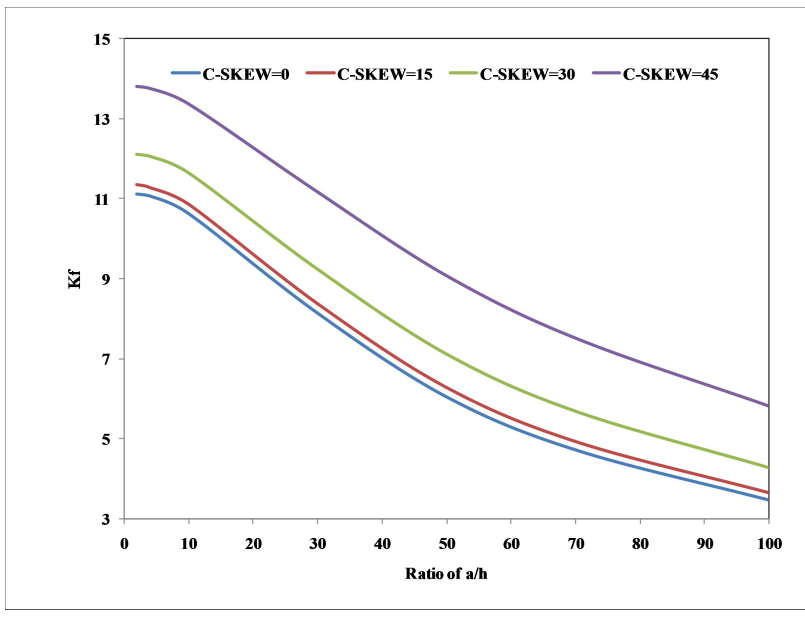

Figure 8: $\mathrm{K}_{f} \mathrm{v} / \mathrm{s}$ values of a/h ratio for laminated clamped antisymmetric cross-ply $\left(0^{\circ} / 90^{\circ} / \mathrm{C} / 0^{\circ} / 90^{\circ}\right)$ skew sandwich plates

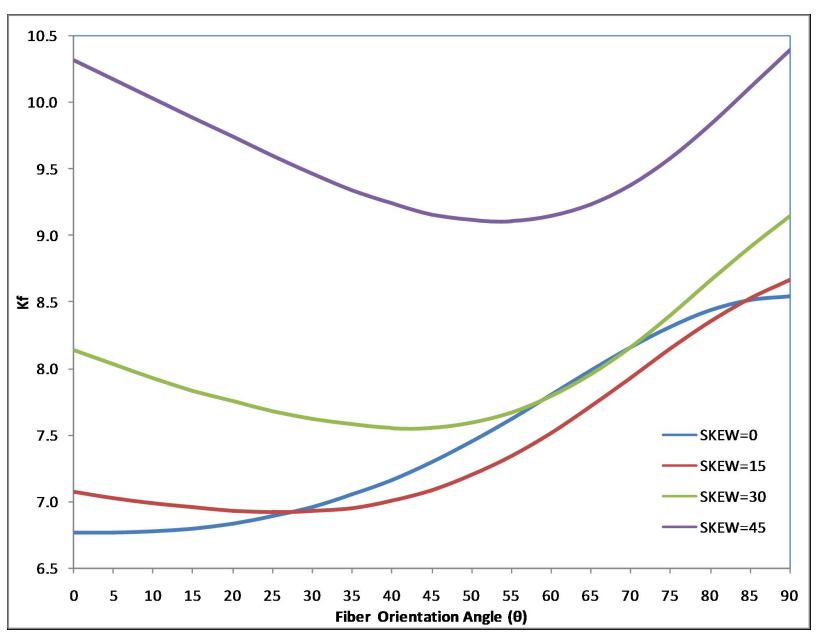

Figure 9: $\mathrm{K}_{f}$ values for laminated simply supported symmetric $\left(\theta^{\circ} / \mathrm{C} / \theta^{\circ}\right)$ angle-ply skew sandwich plates.

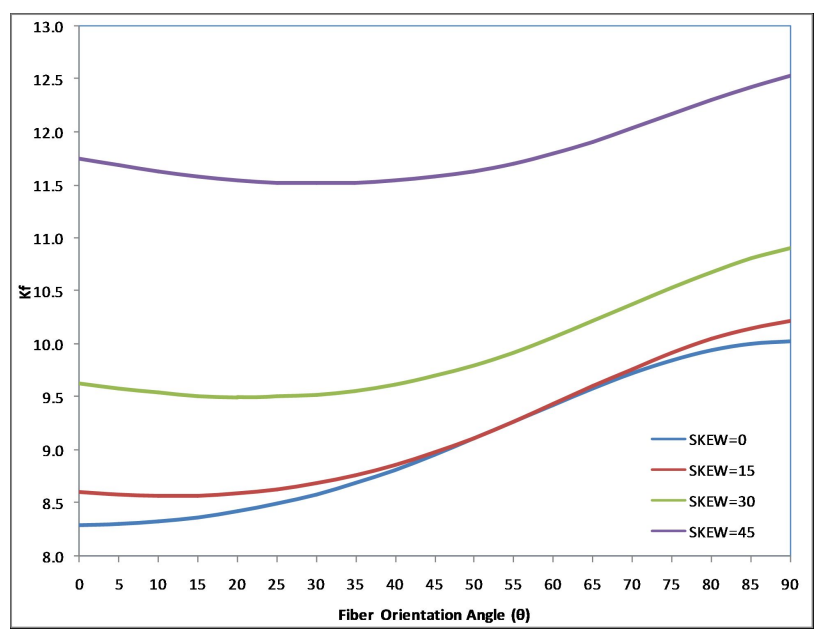

Figure 10: $\mathrm{K}_{f}$ values for laminated clamped symmetric $\left(\theta^{\circ} / \mathrm{C} / \theta^{\circ}\right)$ angle-ply skew sandwich plates

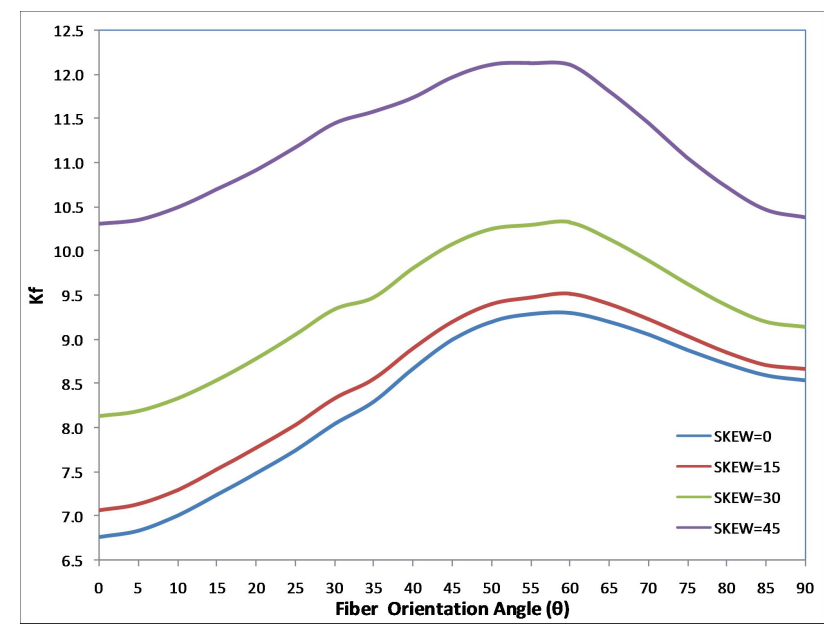

Figure 11: $\mathrm{K}_{f}$ values for laminated simply supported symmetric $\left(\theta^{\circ} /-\theta^{\circ} / \mathrm{C} /-\theta^{\circ} / \theta^{\circ}\right)$ angle-ply skew sandwich plates.

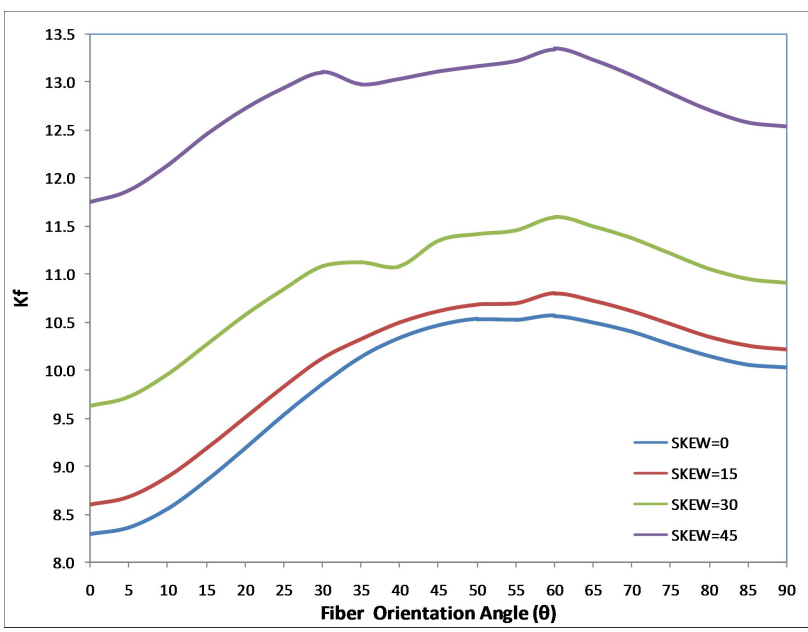

Figure 12: $\mathrm{K}_{f}$ values for laminated clamped symmetric $\left(\theta^{\circ} /-\theta^{\circ} / \mathrm{C} /-\theta^{\circ} / \theta^{\circ}\right)$ angle-ply skew sandwich plates.

\section{Conclusion}

Sandwich skew plates exhibit excellent high stiffness to weight ratio as compared to other laminated structures. The material properties at the interface of the face sheet and core components create complexities to accurately evaluate the mechanics of the sandwich skew plates by the analytical method. The finite element method (FEM) provides the flexibility in designing the structure and recording the response of the skew sandwich plate effortlessly. The present analysis uses CQUAD4 and CQAUD8 elements to evaluate the vibration response of the skew sandwich plate. A convergence study is performed by imposing simply supported and clamped boundary edge conditions. Results obtained by the present method are validated with 
those available in the literature. Aspect ratio, skew angle, the thickness of face sheet and core, number of layers in the face sheet, edge conditions, etc are considered in evaluating vibration response of skew sandwich plates. Concluding remarks are made after performing numerical analysis as:

- Both CQUAD4 and CQUAD8 elements have good agreement with the available literature results. But CQUAD8 element yields more converged, accurate results since the element has 8 nodes while CQUAD4 has 4 nodes.

- The number of layers in the face sheet, when increased, the $\mathrm{K}_{f}$ initially increases up to 4 layers due to the initial increase in the stiffness of the face sheet, after that the change is constant or negligible.

- When increasing the core thickness (increasing $\mathrm{t}_{c} / \mathrm{t}_{f}$ and $\mathrm{a} / \mathrm{h}$ ratios) an increase in total plate thickness, the stiffness of the plate decreases, $\mathrm{K}_{f}$ value decreases considerably for a given skew angle. Higher core thickness does not contribute to stiffness and vibration response of the skew sandwich plate.

- While the skew angle is increased, the side length shortens. This leads to an increase in stiffness of the skew sandwich plate. Because of which the increased value of $\mathrm{K}_{f}$ is observed for a given ratio of $\mathrm{t}_{c} / \mathrm{t}_{f}$ and $\mathrm{a} / \mathrm{h}$.

- Considerable influence is observed while studying fiber orientation on the sandwich skew plate for vibration response. For 3 layers and 5 layers symmetrically laminated composite sandwich plate, the value of $\mathrm{K}_{f}$ initially decreases then increases. A similar variation can be seen [5] for both simply supported and clamped boundary conditions.

- The value of $\mathrm{K}_{f}$ is higher for all side clamped condition than all sides simply supported. In the clamped edge condition, the plate becomes stiffer than simply supported edge condition.

Acknowledgments: The authors would like to thank the Management and Principal of GM Institute of Technology, Davangere, Karnataka, for the kind encouragement and constant support provided.

Funding information: The authors state no funding involved.

Author contributions: All authors have accepted responsibility for the entire content of this manuscript and approved its submission.
Conflict of interest: The authors state no conflict of interest.

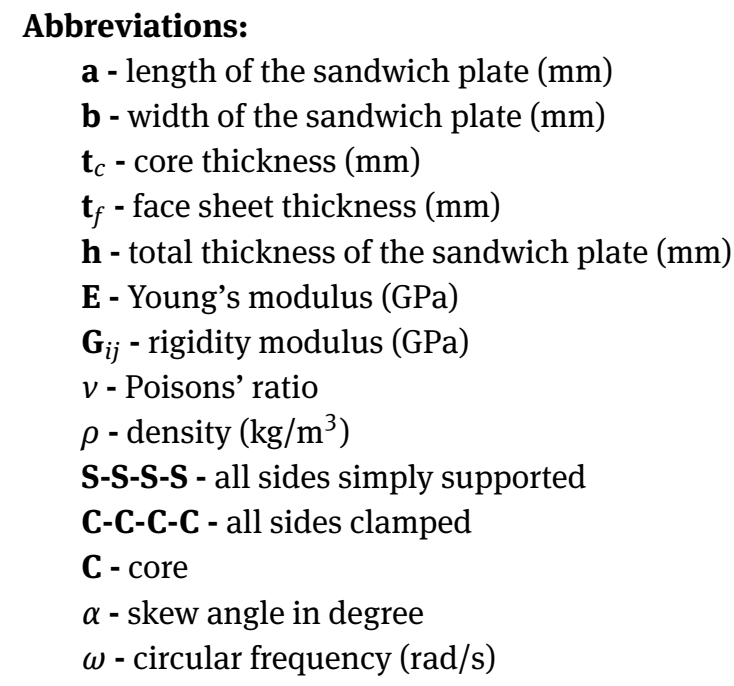

\section{References}

[1] Kanematsu HH, Hirano Y, lyama H. Bending and Vibration of CFRP-Faced Rectangular Sandwich Plates. Comp Struct. 1988;10(2):145-63.

[2] Ibrahim M, Rizk MN, Farah A. Dynamic Analysis of Unbalanced Anisotropic Sandwich Plates. J Eng Mech Div. 1981;107(2):405-18.

[3] Lee LJ, Fan YJ. Bending and Vibration Analysis Of Composite Sandwich Plates. Comput Struc. 1996;60(1):103-12.

[4] Attaf B. On the free vibration of honeycomb sandwich plates, IABSE Symposium Structures for the Future - The Search for Quality. New Dehli, India. 1999:292-293

[5] Wang CM, Ang KK, Yang L, Watanabe E. Free Vibration of Skew Sandwich Plates with Laminated Facings. J Sound Vibrat. 2000;235(2):317-40.

[6] Kant T, Swaminathan K. Analytical Solutions for Free Vibration of Laminated Composite and Sandwich Plates Based on A Higher-Order Refined Theory. Comp Struct. 2001;53(1):73-85.

[7] Chakrabarti A, Sheikh AH. Vibration of Laminate-Faced Sandwich Plate by a New Refined Element. J Aerosp Eng. 2004;17(3):123-34.

[8] Park T, Lee SY, Seo JW, Voyiadjis GZ. Structural dynamic behavior of skew sandwich plates with laminated composite faces. Compos, Part B Eng. 2008;39(2):316-26.

[9] Kapuria S, Kulkarni SD. An improved discrete Kirchhoff quadrilateral element based on third-order zigzag theory for static analysis of composite and sandwich plates. Int J Numer Methods Eng. 2007;69(9):1948-81.

[10] Kapuria S, Kulkarni SD. Free vibration analysis of composite and sandwich plates using an improved discrete Kirchhoff quadrilateral element based on third-order zigzag theory. Comput Mech. 2008;42(6):803-24.

[11] Malekzadeh K, Malek-Mohammadi H. Free Vibration and Buckling Analysis of Sandwich Panels with Flexible Cores Using an 
Improved Higher-Order Theory. J Solid Mech. 2017;9(1):39-53.

[12] Chen JE, Zhang W, Sun M, Yao MH, Liu J. Free vibration analysis of composite sandwich plates with different truss cores. Mech Adv Mater Structures. 2017;25(9):701-13.

[13] Pavan K, Srinivasa CV. On Buckling and Free Vibration Studies of Sandwich Plates and Cylindrical Shells: A Review. J. Thermoplast. Compos. Mater. 2018;33(5):673-724.

[14] Atteshamuddin SS, Yuwaraj MG. On the Free Vibration Analysis of Laminated Composite and Sandwich Plates: A Review of Recent Literature with Some Numerical Results. Comp Struct. 2015;129:177-201.

[15] Atteshamuddin SS, Yuwaraj MG. On the Free Vibration of Angle Ply Laminated Composite and Soft-Core Sandwich Plates. J Sandw Struct Mater. 2016;19(6):679-711.

[16] Belarbi MO, Tati A, Ounis H, Benchabane A. Development of A 2D Isoparametric Finite Element Model Based on the Layerwise Approach for the Bending Analysis of Sandwich Plates. Struct Eng Mech. 2016;57(3):473-506.

[17] Belarbi MO, Tati A, Ounis H, Khechai A. On the Free Vibration Analysis of Laminated Composite and Sandwich Plates: A Layerwise Finite Element Formulation. Lat Am J Solids Struct. 2017;14(12):2265-90.

[18] Nasihatgozara M, Khalili SM. Free Vibration of Thick Sandwich Plate using Higher Order Shear Deformation Theory and DQM for Difference Boundary Conditions. J Appl Comput Mech. 2017;3(1):16-24.

[19] Yuan WX, Dawe DJ. Free vibration of sandwich plates with laminated faces. Int J Numer Methods Eng. 2002;54(2):195217.

[20] Ajay KG, Rakesh KK, Kant K. Free Vibration of Skew Fiberreinforced Composite and Sandwich Laminates using a Shear Deformable Finite Element Model. J Sandw Struct Mater. 2006;8(1):33-54.

[21] Nayak AK, Moy SS, Shenoi RA. Free Vibration Analysis of Composite Sandwich Plates Based on Reddy's Higher-Order Theory. Compos, Part B Eng. 2002;33(7):505-19.

[22] Chalak HD, Anupam C, Abdul HS, Mohammad AI. $C_{0}$ FE Model Based on HOZT for the Analysis of Laminated Soft Core Skew Sandwich Plates: bending and Vibration. Appl Math Model. 2014;38(4):1211-23.

[23] Srinivasa CV, Suresh Y], Prem Kumar WP. Free Flexural Vibration Studies on Skew Plates, Int. J. Eng Sci Tech. 2012;4(4):1324.

[24] Srinivasa CV, Suresh YJ, Prem Kumar WP. Experimental and Finite Element Studies on Free Vibration of Skew Plates, Int. J Appl Mech Eng. 2014;19(2):365-77.

[25] Srinivasa CV, Suresh YJ, Prem Kumar WP. Experimental and Finite Element Studies on Free Vibration of Skew Plates, Int. J. Adv Struct Eng. 2014;6:48-59.

[26] Wang X, Liang X. Free vibration of soft-core sandwich panels with general boundary conditions by harmonic quadrature element method. Thin-walled Struct. 2017;113:253-61.

[27] Pankaj K, Subrata Kumar P, Trupti RM. Effect of Skew Angle on Free Vibration Responses of Sandwich Composite Plate. Int. J. Res. Mech. Eng Technol. 2017;7(1):21-5.

[28] Pavan K, Srinivasa CV. Free vibration studies on skew sandwich plates by FEM. Int Conf Comput Eng Mater Sci, 17-18th July 2020, GMIT-Davangere, Karnataka, India. 2020;925: 012024.

[29] Raville ME, Ueng CE. Determination of Natural Frequencies of
Vibration of a Sandwich Plate. Exp Mech. 1967;7(11):490-3.

[30] Reddy JN, Phan ND. Stability and vibration of isotropic, orthotropic, and laminated plates according to a higher-order shear deformation theory. J Sound Vibrat. 1985;98(2):157-70.

[31] Ashish KS, Dinesh K. Postbuckling behavior of functionally graded CNT-reinforced nanocomposite plate with interphase effect. Non-lin Eng. 2019;8(1):496-512.

[32] Chen G, Peng J. An Experimental Investigation of Mode Shift of Cantilever Flexible Plate Coupled with Fluid, Non-lin Eng. 2012;1(0):59-66.

[33] Tounsi A, Alimirzaei S, Mohammadimehr M. Nonlinear analysis of viscoelastic micro-composite beam with geometrical imperfection using FEM: MSGT electro-magneto-elastic bending, buckling, and vibration solutions. Struct Eng Mech. 2019;71(5):485-502.

[34] Aman G, Chalak HD. A review on analysis of laminated composite and sandwich structures under hygrothermal conditions. Thin-walled Struct. 2019;142:205-26.

[35] Tounsi A, Bousahla AA, Zarga D, Bourada F, Mahmoud SR. Thermomechanical bending study for functionally graded sandwich plates using a simple quasi-3D shear deformation theory. Steel Compos Struct. 2019;32(3):389-410. 